\title{
HUBUNGAN PENGETAHUAN MAKANAN CEPAT SAJI (FAST FOOD) DENGAN KEJADIAN DISMENORHOE PADA SISWI KELAS VII DI SMPN 2 JALAKSANA KECAMATAN JALAKSANA KABUPATEN KUNINGAN TAHUN 2018
}

\author{
Evie Soviyati, Siti Nurjannah \\ Sekolah Tinggi Ilmu Kesehatan Kuningan Garawangi \\ evie_sofia73@gmail.com
}

\begin{abstract}
Abstrak
Remaja sering mengalami gangguan menstruasi (dismenorhoe). Salah satu faktor penyebabnya adalah asupan gizi yang kurang baik, makanan cepat saji banyak mengandung asam lemak trans salah satu radikal bebas yang mengandung zat pemicu prostaglandin (Anisa,2015). Studi pendahuluan yang dilakukan pada siswi SMP 2 Jalaksana menunjukkan bahwa sebagian besar siswi belum mengetahui makanan cepat saji dapat mengakibatkan dismenorhoe. Tujuan penelitian untuk mengetahui hubungan pengetahuan makanan cepat saji dengan kejadian dismenorhoe, rumusan masalah 'Adakah hubungan pengetahuan makanan cepat saji dengan kejadian dismenorhoe pada siswi kelas VII di SMPN 2 Jalaksana Tahun 2018?'. Hipotesa penelitian terdapat hubungan antara pengetahuan makanan cepat saji dengan kejadian dismenorhoe. Penelitian menggunakan metode analitik,dengan rancangan cross sectional subjek penelitian siswi kelas VII sebanyak 204, tehnik sampel stratifikasi sampling diperoleh sampel sebanyak 58 siswi, pengumpulan data menggunakan kuesioner dan menggunakan analisis univariat dan bivariat dengan rumus chi square. Hasil analisis univariat dari 58 siswi diperoleh 31(53.4\%) berpengetahuan baik, dan kejadian dismenorhoe adalah 31(53.4\%). Analisis bivariat diperoleh nilai $p$-value $(0,01)$, dengan presentasi siswi dengan pengetahuan kurang mendominasi terjadinya dismenorhoe $(99,9 \%)$. Semakin tinggi pengetahuan mempengaruhi perilaku dan sikap siswi dalam mengonsumsi makanan. Kejadian dismenore terjadi akibat penumpukan prostaglandin dalam jumlah banyak, dimana bersumber dari makanan cepat saji. Terdapat hubungan pengetahuan makanan cepat saji dengan kejadian dismenorhoe. Upaya meminimalisasi dampak negatif makanan cepat saji dengan bersikap bijak memilih menu makanan, disertai mengkonsumsi sayuran dan buahbuahan. Selain itu tenaga kesehatan memberikan sosialisasi Gerakan Masyarakat Hidup Sehat di sekolah.
\end{abstract}

Kata Kunci $\quad$ : Pengetahuan, Makanan Cepat Saji, Dismenore.

\section{Pendahuluan}

Dismenorhoe adalah nyeri haid, gangguan ini bersifat subyektif, berat dan intensitasnya sukar dinilai, walaupun frekuensi dismenorhoe cukup tinggi dan penyakit ini sudah lama dikenal, namun sampai sekarang patogenesisnya belum dapat dipecahkan (Sarwono, 2010: 229) Studi ini juga melaporkan bahwa dismenore menyebabkan $14 \%$ remaja sering tidak masuk sekolah (Bonde dkk, 2014). Malaysia prevalensi dismenore pada remaja sebanyak 62,3\% (Ningsih, 2011), sedangkan menurut Komal Atta dkk dalam penelitian di Departemnt of Physiology, University Medical and Dental College, The University of Faisalabad Pakistan didapatkan dismenorhoe terjadi pada $86,5 \%$ anak perempuan. Mayoritas melaporkan gejala PMS kram $(32,7 \%)$, nyeri perut $(44,7 \%)$, perubahan suasana hati $(40 \%)$. 
JURNAL ILMU KESEHATAN BHAKTI HUSADA:

HEALTH SCIENCES JOURNAL, Vol. 10 No. 01, JUNI 2019 DOI:

Stresor utama untuk dismenore adalah stres $(81,8 \%, p=0,018)$.

Indonesia angka kejadian dismenore terdiri dari $54,89 \%$ dismenore primer dan 9,36\% dismenore sekunder, sedangkan angka kejadian dismenore di Jawa Barat cukup tinggi, hasil penelitian didapatkan kejadian sebanyak $54,9 \%$ wanita mengalami dismenore, terdiri dari $24,5 \%$ mengalami dismenore ringan, $21,28 \%$ mengalami dismenore sedang dan 9,36\% mengalami dismenore berat (Rahayu, 2015).

Penyebab terjadinya dismenore salah satunya adalah mengkonsumsi makanan cepat saji (fast food). Menurut Anisa (2015), makanan cepat saji (fast food) merupakan salah satu faktor yang menyebabkan terjadinya dismenore. Makanan cepat saji (fast food) dapat diartikan sebagai makanan yang dapat disiapkan dan disajikan dengan cepat (Sulistijani, 2012:43). Beberapa makanan yang tergolong makanan cepat saji modern antara lain hamburger, ayam goreng kentucky, pizza, spagetty, sosis, chicken nugget. Menurut penelitian 15-20\% remaja di Jakarta mengonsumsi fried chicken dan burger sebagai makan siang dan 16\% mengonsumsi pizza dan spaggethi. Bila makanan tersebut sering dikonsumsi secara terus-menerus dan berlebihan dapat mengakibatkan gizi lebih (Mudjianto, 2014).

Kurangnya pengetahuan dan salahnya konsepsi tentang kebutuhan pangan akan mempengaruhi konsumsi pangan (Suhardjo, 2016:25). Pengetahuan siswa tentang makanan cepat saji adalah pengetahuan siswa tentang pengertian makanan cepat saji, pemahaman tentang cara mengkonsumsi makanan cepat saji, penggunaan pengetahuan makanan cepat saji dalam kehidupan sehari hari, jenis jenis makanan cepat saji, dampak mengkonsumsi makanan cepat saji terhadap kesehatan.

Berdasarkan hasil penelitian Janah (2016) dari 77 remaja putri sebagian besar memiliki pengetahuan baik sebanyak 75 orang $(97,4 \%)$. Berdasarkan hasil penelitian
Indahwati (2017), hasil penelitian terhadap 63 responden terdapat 35 responden (55.6\%) sering menggonsumsi makanan cepat saji dengan kejadian dismenore 27 responden $(42.9 \%)$ dan 8 responden (12.7\%) tidak dismenore, sedangkan 28 responden $(44.4 \%)$ jarang menggonsumsi fast food didapatkan 14 responden $(22.2 \%)$ dismenore dan 14 responden (22.2\%) tidak dismenore.

Berdasarkan hasil studi pendahuluan di SMPN 2 Jalaksana Kecamatan Jalaksana Kabupaten Kuningan, berdasarkan hasil wawancara terhadap 10 orang Siswi, didapatkan hasil bahwa dari 9 orang mengalami dismenore, dari 9 siswi tersebut mengatakan sering mengkonsumsi makanan cepat saji karena cepat dan rasanya lebih enak. Selama ini siswi tidak mengetahui kalau makanan tersebut dapat mengakibatkan terjadinya dismenore.

Berdasarkan uraian tersebut maka penulisan tertarik untuk melakukan penelitian mengenai "Hubungan Pengetahuan tentang Makanan Cepat saji (fast food) terhadap Kejadian Dismenore pada Siswi Kelas VII di SMPN 2 Jalaksana Kecamatan Jalaksana Kabupaten Kuningan Tahun 2018".

\section{Maetode Penelitian}

Penelitian ini termasuk ke dalam jenis penelitian analitik. Rancangan Penelitian cross sectional. Populasi dalam penelitian ini adalah seluruh siswi kelas VII yang berada di SMPN 2 Jalaksana Kecamatan Jalaksana Kabupaten Kuningan sebanyak 204 siswi. Pada penelitian ini pengambilan sampel dilakukan dengan menggunakan teknik stratifikasi random sampling. Dengan menggunakan rumus Slovin Margin of error yang ditetapkan adalah $5 \%$ atau 0,05 . Hasil pembulatan menjadi 58 siswi. Pengambilan sample dengan membagikan kuesioner pada siswi kelas VII. Teknik pengolahan data menggunakan Analisis Univariat dan Analisa Bivariat untuk melihat hubungan pengetahuan tentang makanan cepat saji 
JURNAL ILMU KESEHATAN BHAKTI HUSADA:

HEALTH SCIENCES JOURNAL, Vol. 10 No. 01, JUNI 2019

DOI:

terhadap kejadian dismenorhoe dengan rumus

chi

square

\section{Hasil}

Tabel 1 Distribusi Frekuensi Pengetahuan siswi kelas VII tentang makanan siap saji

\begin{tabular}{clcc}
\hline No & Pengetahuan & $\mathrm{f}$ & $\%$ \\
& & & \\
\hline 1 & Kurang & 11 & 19 \\
2 & Cukup & 16 & 27.6 \\
3 & Baik & 31 & 53.4 \\
\hline & Total & 58 & 100 \\
\hline
\end{tabular}

Sumber penelitian 2018

Berdasarkan tabel diatas dari 58 siswi terdapat 31 (53.4\%) siswi berpengetahuan Baik

Tabel 2 Distribusi Frekuensi kejadian dismenorhoe

\begin{tabular}{lccc}
\hline No & Kejadian dismenorhoe & $\mathrm{f}$ & $\%$ \\
\hline 1 & Dismenorhoe & 27 & 46,6 \\
2 & Tidak dismenorhoe & 31 & 53,4 \\
\hline Total & 58 & 100 \\
\hline \multicolumn{2}{l}{ Sumber penelitian 2018 }
\end{tabular}

Berdasarkan tabel diatas dari 58 siswi terdapat 31 (53.4\%) siswi tidak mengalami kejadian dismenorhoe

Tabel 3 Hubungan Pengetahuan tentang makanan siap saji dengan kejadian Dismenorhoe

\begin{tabular}{|c|c|c|c|c|c|c|c|c|}
\hline \multirow{3}{*}{ No } & \multirow{3}{*}{ Pengetahuan } & \multicolumn{4}{|c|}{ kejadian dismenore } & \multirow{2}{*}{\multicolumn{2}{|c|}{ Total }} & \multirow{3}{*}{$\begin{array}{c}\text { nilai } \\
p- \\
\text { valu } \\
e\end{array}$} \\
\hline & & \multicolumn{2}{|c|}{ dismenorhoe } & \multicolumn{2}{|c|}{$\begin{array}{c}\text { tidak } \\
\text { dismenorhoe }\end{array}$} & & & \\
\hline & & $\mathrm{n}$ & $\%$ & $\mathrm{~N}$ & $\%$ & $\mathrm{n}$ & $\%$ & \\
\hline 1 & Kurang & 10 & $90,90 \%$ & 1 & $9,10 \%$ & 11 & 100 & 0,01 \\
\hline 2 & Cukup & 14 & $87,50 \%$ & 2 & $12,50 \%$ & 16 & 100 & \\
\hline 3 & Baik & 3 & $9,70 \%$ & 28 & $90,30 \%$ & 31 & 100 & \\
\hline Total & & 27 & $46,60 \%$ & 31 & $53,40 \%$ & 58 & 100 & \\
\hline
\end{tabular}

Berdasarkan tabel diatas 11 siswi berpengetahuan kurang dan mengalami dismenorhoe sebanyak $10(90,9 \%)$, dengan nilai $p$-value 0,00 sehingga terdapat hubungan antara pengetahuan dengan kejadian dismenorhoe.

\section{Pembahasan}

\section{Distribusi Frekuensi Pengetahuan siswi Kelas VII Tentang Makanan Siap Saji}

Dari 58 responden sebagian besar memiliki pengetahuan baik sebanyak 31 responden $(53,4 \%)$. Menurut Bloom yang dikutip Sukardi (2011:75), mendefenisikan teori mengenai pengetahuan yaitu kemampuan yang dimilki oleh seseorang untuk mengingat dan mengungkapkan 
JURNAL ILMU KESEHATAN BHAKTI HUSADA:

HEALTH SCIENCES JOURNAL, Vol. 10 No. 01, JUNI 2019 DOI:

kembali pengetahuan, rumus-rumus, konsep, prinsip, materi dan kejadian baik pada halhal yang umum maupun hal-hal yang khusus. Hal ini tidak sesuai dengan dengan (Suhardjo, 2016:25). Bahwa kurangnya pengetahuan dan salahnya konsepsi tentang kebutuhan pangan akan mempengaruhi konsumsi pangan. Gangguan gizi disebabkan oleh kurangnya pengetahuan kurang gizi atau kemampuan untuk menerapkan informasi tersebut dalam kehidupan sehari-hari. Begitu pula dengan hasil penelitian ini sesuai dengan penelitian Triyanti (2016), menyatakan bahwa dari 70 responden sebagian besar memiliki pengetahuan rendah (kurang) sebanyak 55\% terhadap dengan Perilaku Konsumsi Makanan Cepat Saji (Fast Food) pada Siswa Sekolah Menegah Atas Pembangunan Laboratorium Universitas Negeri Padang.

\section{Distribusi Frekuensi kejadian dismenorhoe}

Berdasarkan hasil penelitian dari 58 siswi terdapat $31 \quad(53.4 \%)$ siswi tidak mengalami kejadian dismenorhoe dan 27 (46,6\%). Menurut Smeltzer dan Bare (2004) dalam Kusmiran (2014:113), faktor resiko terjadinya dismenore diantaranya menarche pada usia lebih awal, rentang usia normal terjadinya menarche biasanya dengan usia rata-rata 12 tahun. Menarche pada usia lebih awal menyebabkan alat-alat reproduksi belum berfungsi secara optimal dan belum siap mengalami perubahanperubahan sehingga timbul nyeri ketika menstruasi. Sejalan dengan penelitian Indahwati (2017), dari 63 responden sebagian besar mengalami kejadian dismenore sebanyak $65,1 \%$. Hasil kejadian siswi yang mengalami dismenohoe hanya selisih sedikitdengan yang tidak mengalami dismenorhoe. Hal ini disebabkan oleh berbagai faktor yaitu usia, usia menarche dini, lama menstruasi, riwayat keluarga, status gizi, kebiasaan olahraga dan diet atau pola makan makanan siap saji.

Hubungan Pengetahuan tentang makanan siap saji dengan kejadian Dismenorhoe
Berdasarkan hasil penelitian dari 58 siswi, 11 siswi berpengetahuan kurang dan mengalami dismenorhoe sebanyak $10(90,9 \%)$, dengan nilai p-value 0,00 sehingga terdapat hubungan antara pengetahuan dengan kejadian dismenorhoe. Hal ini sependapat Bloom yang dikutip Sukardi (2011:75) dengan Pengetahuan yang dimiliki seseorang dapat mengembangkan potensi dan kemampuan secara maksimum untuk mengambil keputusan dalam memecahkan masalah yang dihadapinya untuk menyesuaikan diri.

Pengetahuan siswa tentang makanan siap saji adalah pengetahuan siswa tentang pengertian makanan siap saji, pemahaman tentang cara mengkonsumsi makanan siap saji, penggunaan pengetahuan makanan cepat saji dalam kehidupan sehari hari, jenis jenis makanan cepat saji, dampak mengkonsumsi makanan cepat saji terhadap kesehatan. Perilaku yang didasari oleh pengetahuan akan lebih langgeng daripada perilaku yang tidak didasari pengetahuan.(Notoatmodjo,2012:127)

Menurut Anisa (2015), makanan siap saji banyak mengandung asam lemak trans yang merupakan salah satu radikal bebas.. Salah satu fungsi fosfolipid adalah sebagai penyedia asam arakidonat yang akan disintesis menjadi prostaglandin. Prostaglandin berfungsi membantu rahim berkontraksi dan mengeluarkan lapisan rahim selama periode menstruasi. Jadi, pada wanita yang mengalami nyeri haid atau dismenore ada penumpukan prostaglandin dalam jumlah yang terlalu banyak, sehingga menyebabkan terjadinya dismenore.

\section{Simpulan}

Berdasarkan hasil penelitian tentang gambaran pengetahuan tentang makanan siap saji terhadap kejadian dismenorhoe pada siswi kelas VII di SMPN 2 Jalaksana Kecamatan Jalaksana Kabupaten Kuningan Tahun 2018 maka penulis membuat kesimpulan sebagai berikut : dari 58 siswi sebagian besar memiliki pengetahuan kurang sebanyak baik sebanyak $31(53,4 \%)$, 
JURNAL ILMU KESEHATAN BHAKTI HUSADA:

HEALTH SCIENCES JOURNAL, Vol. 10 No. 01, JUNI 2019 DOI:

dan mengalami kejadian dismenore sebanyak $27(46,6 \%)$ dari 11 orang siswi yang pengetahuan kurang terdapat 10 orang yang mengalami kejadian dismenore sebanyak 90.90\%. Hal ini menunjukan pengetahuan yang dimiliki seseorang dapat mengembangkan potensi dan kemampuan secara maksimum untuk mengambil keputusan dalam memecahkan masalah yang dihadapinya untuk menyesuaikan diri, walaupun sebagian pendidikan siswi baik tetapi tidak menutup kemungkinan karena beberapa faktor yang mempengaruhi. Menurut Triyanti (2014) konsumsi remaja terhadap makanan siap saji disebabkan oleh adanya pengaruh-pengaaruh intern yang berasal dari dalam diri siswa yaitu pengetahuan, persepsi, emosi serta motivasi mengenai makanan siap saji.

\section{Saran}

Siswi diharapkan meningkatkan pengetahuannya mengenai makanan siap saji sehingga dapat lebih bijak dalam memilih menu makanan, selingi dengan mengkonsumsi buah dan sayur. Untuk pengelola sekolah bekerjasama dengan instansi kesehatan terkait/tenaga kesehatan dalam upaya sosialisasi gerakan hidupsehat dilingkungan sekolah.

\section{Daftar Pustaka}

Andrew, G. (2009). Buku ajar kesehatan reproduksi wanita. Jakarta: EGC.

Badriah, DL. (2012). Metodologi Penelitian Ilmu-ilmu Kesehatan. Bandung: Multazam.

Bobak, I. (2014). Buku Ajar Keperawatan Maternitas. Edisi 4. Jakarta: EGC.

Budiarto, E. (2009). Biostatika untuk kedokteran dan Kesehatan Masyarakat. Jakarta: EGC.

Hendrik. (2016). Problema Haid: Tinjauan Syariat Islam Dan Medis. Solo: PT Tiga Serangkai Pustaka Mandiri

Hill, MG. (2012). Nutrition Almanac. Jakarta: Gramedia Pustaka.

Khomsan. (2014). Pangan dan Gizi untuk Kesehatan. Jakarta: PT Raja. Grafindo Persada.

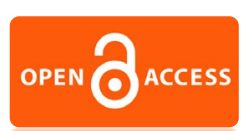

Kusmiran, E. (2014). Kesehatan Reproduksi Remaja dan Wanita. Bandung: Salemba Medika.

Manuaba. (2010). Ilmu Kebidanan Penyakit Kandungan dan KB. Jakarta: EGC.

Notoatmodjo, S. (2012). Metodotogi Penelitian Kesehatan. Bandung: Rineka Cipta.

Nursalam (2013). Konsep dan Penerapan Metodologi Penelitian Ilmu Keperawatan Pedoman Skripsi, Tesis dan Instrumen Penelitian Keperawatan. Jakarta: Salemba Medika.

Potter, P.A. \& Perry, A.G. (2016). Buku ajar fundamental keperawatan: Konsep, proses, dan praktik volume 2. Edisi 4. Jakarta: EGC.

Proverawati dan Misaroh. (2009). Menarche Menstruasi Pertama Penuh Makna. Yogyakarta: Nuha Medika.

Prawiroharjo, (2010). Ilmu Kebidanan. Jakarta: Yayasan Bina Pustaka Sarwono Prawirohardjo.

Ranti. (2014). Kesehatan dan Gizi. Jakarta: PT.Asdi Mahasatya..

Sulistijani. D. A. (2012). Sehat dengan Menu Berserat. Jakarta: Trubus Agriwidya.

Wawan dan Dewi. (2011). Pengetahuan, Sikap, dan Prilaku Manusia. Yogyakarta: Nuha Medika.

Anisa, MV. (2015). Hubungan Status Gizi, Menarche Dini, dan Perilaku Mengonsumsi Makanan Cepat Saji (Fast Food) dengan Kejadian Dismenore Primer pada Siswi SMAN 13 Bandar Lampung. Skripsi. http://digilib.unila.ac.id. Diunduh tanggal 13 Februari 2018.

Muliany, R. (2015). Daftar Kandungan Zat Gizi Serat dan Indeks Glikemik Dalam Penukar Berbagai Hidangan Indonesia dan Makanan Siap Santap Barat. Undergraduate Thesis. Program Studi Ilmu Gizi UNDIP. http://repository.usu.ac.id. Diunduh tanggal 13 Februari 2018.

Ningsih. (2011). Efektifitas Paket Pereda Terhadap Intensitas Nyeri pada Remaja dengan Dismenore di SMAN Kecamatan Curup. Tesis. http://lib.ui.ac.id.pdf. Diunduh tanggal 13 Februari 2018.

Oktaviani. (2012). Hubungan Kebiasaan Konsumsi Fast Food, Aktivitas Fisik, Pola Konsumsi, Karakteristik Remaja 
Orang Tua dengan Indeks Massa Tubuh (IMT). Studi Kasus pada Siswa SMA Negeri 9 Semarang Tahun 2012).1(2):542-553.

http://repository.usu.ac.id. Diunduh tanggal 13 Februari 2018.

Triyanti. (2014). Hubungan Pengetahuan mengenai Makanan Cepat Saji (Fast Food) dengan Perilaku Konsumsi Makanan Cepat Saji (Fast Food) pada Siswa Sekolah Menegah Atas Pembangunan Laboratorium Universitas Negeri Padang. Jurnal Kesehatan Volume 5 Nomor 1 Tahun
2014. http://ejournal.unp.ac.id. Diunduh tanggal 26 Agustus 2018.

Novia dan Puspitasari. (2008). Faktor Resiko yang Mempengaruhi Kejadian Dysmenorrhea. The Indonesian Journal of Public Health, Volume 1 NO. 2 hal 4.96-104. http://eprints.ums.ac.id. Diunduh tanggal 13 Februari 2018.

Janah IC. (2016). Kebiasaan Konsumsi Makanan Cepat Saji pada Siswa Kelas VIII SMP Negeri 1 Yogyakarta. Jurnal Kesehatan Volume 5 No 5 Tahun 2016. http://journal.student.uny.ac.id.

Diunduh tanggal 26 Agustus 2018. 